Article

\title{
Deliberative Ecological Economics for Sustainability Governance
}

\section{Christos Zografos ${ }^{1, *}$ and Richard B. Howarth ${ }^{2}$}

1 Institut de Ciència i Tecnologia Ambientals (ICTA), Universitat Autònoma de Barcelona, ETSE QC/3107, 08193 Bellaterra, Barcelona, Spain

2 Environmental Studies Program, Dartmouth College, HB 6182, 113 Steele Hall, Hanover, NH 03755, USA; E-Mail: RBHowarth@ Dartmouth.edu

* Author to whom correspondence should be addressed; E-Mail: christos.zografos@uab.cat; Tel.: +34-93-586-8260; Fax: +34-93-581-3331.

Received: 29 June 2010; in revised form: 26 October 2010 / Accepted: 27 October 2010 / Published: 29 October 2010

\begin{abstract}
We discuss the recent emergence of 'deliberative ecological economics', a field that highlights the potential of deliberation for improving environmental governance. We locate the emergence of this literature in the long concern in ecological economics over the policy implications of limited views of human action and its encounter with deliberative democracy scholarship and the model of communicative rationality as an alternative to utilitarianism. Considering criticisms over methods used and the focus of research in deliberative decision-making, we put forward a research agenda for deliberative ecological economics. Given the promising potential of deliberative processes for improving the effectiveness and legitimacy of environmental decision-making, work in this area could help advance both theory and practice in environmental governance.
\end{abstract}

Keywords: sustainability governance; preference formation; deliberative democracy; environmental decision-making; ecological economics

\section{Introduction}

"Picture a pasture open to all". With this quasi-bucolic image, Garrett Hardin starts his description of how the Tragedy of the Commons unfolds in his well-known 1968 article in Science. Addressing 
the Pacific Division of the American Association for the Advancement of Science which he presided over at the time (the article is a reprint of his address), Hardin used the parable of 'the commons' to support his argument on the need to effect a moral transformation in governance through regulation and education in order to deal with the issue of overpopulation. Hardin argued that in a finite world, one's decision to give birth implied reducing available resources for the rest, and paralleled this decision to that of using resources in what he called 'a commons'. Using the example of a commoner deciding whether to add one more animal to his herd [1], Hardin posed that:

As a rational being, each herdsman seeks to maximize his gain. Explicitly or implicitly, more or less consciously, he asks, "What is the utility to me [2] of adding one more animal to my herd?" [3]

He then went on to explain that this utility has a positive and a negative component, the former consisting in the herdsman reaping benefits from selling additional animal products and the latter mainly comprising the overgrazing created by the additional animal. However, the adverse effects of overgrazing are shared by all commoners, which results in our commoner's utility being negatively affected only by a fraction of the whole negative impact making the decision to add one more animal in the herd as the only sensible course of action. With this logic, our herdsman carries on adding constantly more animals to his herd. What's more, what is reasonable to him seems reasonable to the rest of the commoners. Thus each and every rational herdsman sharing a commons does the same, i.e., adds more animals to his herd. That leads Hardin to conclude that:

Therein is the tragedy. Each man is locked into a system that compels him to increase his herd without limit - in a world that is limited. Ruin is the destination toward which all men rush, each pursuing his own best interest in a society that believes in the freedom of the commons. Freedom in a commons brings ruin to all. [3]

In the last forty years, numerous objections have been raised against Hardin's assumptions as well as the implications of his conclusions. Nevertheless, the model of human action he put forth has been extensively used to justify and indeed legitimise natural resource management policies promoted by national governments and influential international organisations (e.g., the World Bank). Given some adverse social implications of those policies, several scholars have argued in favour of using other, broader models of human action when analysing environmental decision-making [4].

The aim of this paper is to explore the challenges this agenda poses for research and praxis in ecological economics. Ecological economics emerged as a field in the late 1980s in response to perceived deficiencies in neoclassical economics and its application to environmental policy and governance. On the one hand, ecological economists have sought to understand the links between economic and biophysical systems: how economic activity is supported by the throughput of energy and material flows; how resource depletion and environmental degradation affect the provisioning of ecosystem services; and how biophysical limits constrain the sustainable scale of production and consumption. In this sense, ecological economics is potentially understood as a materialist, empiricist science: Costanza [5] defined the field as "the science and management of sustainability."

Yet ecological economics is also tied to a long-standing critique of mainstream welfare economics - specifically the notion that environmental values can be reduced to preferences that are 
subject to objective measurement and aggregation. In contrast to this vision of "economism" [6], ecological economists have emphasized the socially constructed nature of preferences and the role of moral principles in justifying environmental policies. Daly [7], for example, calls for restructuring economic institutions in a manner that respects both the biophysical limits imposed by nature and the "ultimate end" of society as defined by philosophical and spiritual engagement. This framing explicitly rejects the dichotomy between facts and values that underlies positivism.

In a similar vein, ecological economists have long argued that informing environmental policy decisions requires a "post-normal" or problem-oriented approach to scientific inquiry that is values-sensitive and engaged with the interests and knowledge of lay stakeholders [8]. This highlights the point that ecological economics is not simply a subdiscipline of economics, but rather a transdisciplinary field that seeks to understand and manage the links between the economy, the biosphere, and the social structures that support and sustain human flourishing.

In the succeeding sections of this paper, we present a body of recent ecological economics research that moves beyond the stylized behavioral model that gives rise to the tragedy of the commons. We begin by describing some undesirable implications of using Hardin's view of human action to analyse environmental issues to derive policy conclusions. We then move on to briefly explain some key theoretical arguments regarding the limitations of this model and to present an alternative model of human action (communicative rationality) as a basis for developing effective and legitimate environmental decision-making. Furthermore, the paper describes the work of ecological economists in this area-which has given rise to a body of literature we call 'deliberative ecological economics' [9] —and sketches the main traits of this work, to finally conclude with an outline of possible future research issues in that area emerging as a response to perceived weaknesses of existing research.

\section{Environmental Policy Implications of 'Rational' Action}

Hardin's explanation of environmental degradation has been duly criticised from various perspectives. First and foremost, it has been pointed out that his model does not describe a common property regime but rather an open access situation where the use of natural resources is not regulated by any rules at all. Instead, supporters of this thesis argue, 'commons' are well-defined systems governed by mutually beneficial and compelling regulations [10]. Others have taken issue with some of Hardin's suggestions that privatising commonly-held resources could be the best solution for protecting valuable resources as it gives a private incentive to conserve them for private benefit. Critics point out that commons have successfully supported populations living in marginal (in terms of fertility potential) areas [11] and that commons privatisation results in making a few already rich landowners even richer [12] while transforming commoner populations to social and economic pariahs [13]. Enclosure of the commons results in the private appropriation of what used to be a common benefit [14]. Moreover, Hardin's critics argue that practice shows it is actually private owners (enclosers) who not only benefit from but also contribute to the demise of the commons, as they move in to aggressively exploit resources to their full potential and then quickly sell them off in order to acquire more promising resources in other areas [11].

A central aspect of Hardin's article, which has also been duly criticised, refers to his treatment of human behaviour as depicted in his example of the 'rational' herdsman. Specifically, this being is 
meant to make decisions by carefully weighing the utility gains and losses of alternative decisions. This is hardly an original view of human action as it is the one adopted by perhaps the most influential branch of economics: neo-classical economics. Standard neo-classical economics textbook definitions of human behaviour have it that rationality entails making decisions after careful weightings of costs and benefits, always opting for that alternative that offers the higher utility gains to oneself. Herbert Simon [15] defines this conception as substantive rationality, contrasting it with the complementary notion of procedural rationality that we discuss below. Philosophically based upon utilitarianism, this narrow definition of rational human behaviour has dominated mainstream economic models during the 20th century. Eventually, economists studying environmental issues also found it useful to adopt it for their analysis. According to this homo economicus model, rational human action as regards how to use environmental resources boils down to the moral stance of egoism, in which individuals seek to maximize their own utility without regard for the interests of others. As a result, individuals look at costs and benefits of alternative actions towards the environment in order to decide which one is best to follow.

Since the mid-80s, Hardin's insights have provided a rational argument for multi-lateral international institutions and western governments to pursue the widespread privatisation of natural resources and massive transfers of communal lands to the state or individuals in developing countries [11]. Institutions such as the World Bank still put forward this logic in order to defend such natural resource management strategies as regards a new category of commons: the 'environmental commons'. In a 2002 article with the telling title 'Global Priority', the then president of the World Bank James D. Wolfensohn explained to the readers of the United Nations Environment Programme (UNEP) official magazine that environmental services such as biodiversity constitute invaluable global commons that are not effectively protected by individual countries as these have "limited economic incentives for taking action on the global environment" [16]. But, Wolfensohn tells us, this is something to be expected as it is exactly in the nature of a global public good such as environmental services to attract decisions taken at the country level that do not adequately reflect their global impacts. Consider for example a developing country rich in biodiverse rainforests but drawn into poverty. Its government would be happy to deplete all resources available in these forests for the country's economic development, no matter if in the course of this use, several ecologically valuable species disappear. Here, Hardin's all-powerful 'rational' herdsman forcefully emerges again, only in this case he comes in the guise of an 'individual country'. The World Bank president further explains that this is what economists describe as a situation where "regional and global externalities are not internalised at the national level" [16]. The author then points out that one of the Bank's tasks is precisely to generate those-previously absent - markets in which global environmental goods and services and global non-market values can be traded. One such example is the Global Environment Facility (GEF) where those values are captured primarily through international resource transfers.

Similarly, the rational actor model of homo economicus underlies the recently established European Union (EU) Emissions Trading Scheme (ETS) and its counterpart the Clean Development Mechanism (CDM) that aim to partly tackle climate change. This pollution permits trading scheme is premised on the idea that industrial polluters will act as 'rational' profit maximisers so that when they cannot afford to reduce their pollution they will opt for buying a permit from more eco-efficient polluters who have already managed to reduce their pollution. As a result, the scheme expects to motivate more 
eco-efficient producers to reduce pollution themselves in the expectation of gaining money from selling spare permits. Alternatively of course, the whole scheme allows 'rational' polluters to invest in CDM projects instead of either trying to reduce their pollution or buy permits. In that case, industrial polluters, again acting as 'rational' profit maximisers, will prefer investing in sustainable projects that 'cancel out' their pollution (e.g., planting a forest or construct a wind farm in a developing country) instead of directly reducing the pollution themselves, as long as the second option is more affordable to them. ETS and CDM are specific examples of institutions set in place to accommodate a profit-maximiser (homo economicus) rationality in order to achieve sustainability goals. Both institutions comprise economic and in particular market-based instruments that are used to achieve sustainable development (halt biodiversity loss and reduce unnecessary pollution). Both of these economic institutions for sustainable development result from policy initiatives of large and influential organisations such as the EU and the World Bank, hence their worldwide impact is considerable.

On the ground, however, conflict hinders the success of GEF initiatives. These conflicts can reach extremities as in the case of the Komodo National Park Collaborative Management Initiative in Indonesia, where park security personnel fatally shot two local fishermen whom they suspected of fishing illegally within the park [17]. Research suggests that several GEF projects overlook critical land tenure and property rights issues and remove control over decision-making and access to areas traditionally used by local indigenous communities (e.g., as hunting sites) [17]. These criticisms point out that GEF projects regularly treat local populations as beneficiaries rather than rights holders and that the whole initiative should adopt policies which secure local people's rights to lands and territories, as well as their free prior and informed consent. Likewise, property rights issues underlie the limitations of ETS. Tradable pollution permits schemes have been criticised for not modifying the existing situation of injustice as regards rights and access to carbon sinks and reservoirs [18]. Critics suggest that climate change policies should instead be looking to create fair shares of environmental space in terms of emissions equity, so that poorer nations are allowed to emit more greenhouse gases to develop and provide their citizens with much needed quality of life (e.g., health care improvements). A similar criticism also applies for the CDM of the ETS scheme, as this transforms local assets into a mortgage for developed economies to continue growing and polluting, removing at the same time control over the use of these resources from the hands of poorer local populations [19] through long-term resource leases and use constraints.

Property rights issues with land and natural resources are at the heart of conflicts and concerns with economic institutions for sustainable development (such as the GEF, ETS and CDM). These mechanisms seem to limit local access to the 'global commons' and reduce local control over decisions made concerning them. The removal of property rights over these resources contributes to a form of environmental injustice as these mechanisms re-distribute costs and benefits from using resources ('global commons') to the disadvantage of poorer local populations. Homo economicus is the discourse used to legitimise and justify such policy instruments that facilitate this resource take-over, which suggests a crucial link between environmental justice and the use of this model of human action for policy analysis. Indeed, homo economicus seems to play a key role in this process: it is the central theoretical concept as regards human behaviour towards natural resources, which supports arguments used to analyse and chart policy that results in value disputes, conflict and injustice. In this way, Hardin's model of human behaviour is used not only to conceptualise environmental problems but also 
to produce conflictive policy solutions. The diagnosis that the existence of facilities to trade externalities would help resolve environmental problems is entrenched in this homo economicus reading of human action towards the environment, which holds that individualistic, yet 'rational' behaviour is responsible for generating environmental problems (e.g., biodiversity loss, excessive pollution). This implies that from an environmental justice perspective, and in particular from the concept's distributional and procedural aspects [20], it would be desirable to seek an alternative model of human action that can be used in the analysis of sustainability policy.

\section{Rational Action: From Instrumental to Deliberative}

Further criticism of homo economicus from within the field of economics has pointed out that the model's profit-maximising view of behaviour is unrealistic as it ignores the fact that human action towards the environment may have broader ethical premises than egoism and that motivation for environmental action is embedded in multiple and possibly incommensurable environmental values and not just monetary ones. Moreover, when such a limited view of human action is used as a platform for the analysis of environmental issues it may end up generating counterproductive or even undemocratic policies, by crowding out environmental values necessary for sustainability or by altogether excluding them.

Based on the observation of incommensurable and lexicographic environmental preferences, some critics have made a strong case that human action towards the environment should be understood in mainly ethical terms [21]. This implies that environmental preferences correspond to ways that agents implicitly or explicitly decide how to answer the question 'what is good and just', which is the essential question in ethics. Importantly, this conception of human action towards the environment does not exclude a concern for individual welfare [22]. Normative ethics, the branch of philosophy dedicated to the study of the question 'what is right and just', postulates three major perspectives when answering this fundamental ethical question [23]: consequentialism, which judges rightness of an action according to its consequences; deontological ethics, which judges the rightness of action according to its keeping with pre-established duties and rules; and proceduralism, which judges the rightness of action according to its keeping with legitimate procedures.

Ecological economists have proposed several models of human behaviour as alternatives to homo economicus. Most of them seem to fall within those categories of ethical action. For example, utilitarianism (either self or other-regarding) fits with a consequentialist mode of answering the ethical question [22]. Hierarchies of decision-making (lexicographic preferences) [24], expressive rationality [25], incommensurability [26], and a concern for protecting the rights of future generations [27] fit quite well with the deontological perspective. Finally, rule-based behaviours such as satisficing [15], behaviour under risk and uncertainty [28], and habitual behaviour [28], which are premised on bounded rationality [15] that acknowledges informational and social constraints on behaviour [29] fit quite well with the procedural outlook. In several occasions [28] environmental and ecological economists urge using these alternative models instead of the unrealistic, limited and limiting homo economicus to conceptualise human behaviour and conduct sustainability policy analysis [30,31].

The need to improve the democratic legitimacy of environmental policies is a key point that underlies the quest for a broader view of human action that would allow considering plural motivations 
and avoid their exclusion from shaping sustainability policy. Norton [32], for example, draws on the Pragmatism of John Dewey [33] to describe an approach to environmental governance that combines elements of constructivism and empiricism. Pragmatism explores the interdependence between values and science in effective problem-solving, emphasizing the role of discourse and deliberation in legitimising both values and factual understandings.

For the purposes of the present discussion, a central aspect of the homo economicus view of human behaviour relates to the understanding of human action as instrumental, that is as a means for achieving predetermined goals, be they specific material (or not) outcomes or the satisfaction of moral principles and values. Here we turn on the contributions of Jürgen Habermas whose ideas have been used in public policy studies and have also been noted in ecological economics [34-36]. Habermas [37] (see also Walzer [38]) considered the influence of instrumental action upon the democratic potential of institutions, associating the degradation of the democratic potential of major spheres of social life (e.g., state, social organisations, etc.) to their being taken over by models of strategic and instrumental rationality. According to him, this logic submits areas of public life under the logic of efficiency and control propagated by forces of economic (market) and administrative (state) rationalisation, which reduce human relations from communicative concerns to instrumental norms.

Instead, Habermas advances communicative action as an alternative to instrumental action. Communicative action is based on the premise that the essence of rational action can also be to reach understanding between oneself and other actors or society in general instead of achieving instrumental goals. Such understanding is generated via inter-subjective communication between actors in the course of which they formulate views (change or else 'shift' their preferences) by reflectively considering the viewpoints of those with whom they communicate. In that sense, the type of action that is rooted on communicative rationality can reflect logics that go beyond instrumental seeking of pre-defined ends, which is the logic of action entrenched in homo economicus. Habermas believes that communicative rationality is better placed than instrumental rationality to advance the democratic development of society through discussion and quest for consensus instead of instrumental action that seeks to achieve one's own ends.

With this in mind, advocates of deliberative democracy have established communicative action as the basis of a model of 'genuine' democracy due to its potential to generate consensus solutions through dialogue, reflection and preference change. Communicative rationality has been adopted by democratic theory to strengthen the argument that a deliberative form of decision-making — which facilitates reflective consideration of preferences-is the most legitimate form of democracy. Dryzek [39] argues that during the last fifteen years democratic theory has taken a 'deliberative turn', which aims to establish deliberation as a source of democratic legitimacy. Deliberative democrats stress the procedural aspects rather than the institutionalized mechanisms (such as elections, parliamentary procedures, etc.) of democratic decision-making [40]. Arguing that those subject to a decision must be provided the ability or opportunity to engage in effective deliberation prior to decision-making in order for a decision to be legitimate, deliberative democrats postulate deliberation as the source of democratic legitimacy of public decisions. Another development related to the recent policy emphasis on deliberation, concerns the failure of the scientific discourse in some cases to provide definitive answers for some environmental issues (e.g., debate on global warming) which has helped substantiate the claim that scientific values are merely one more set of values that needs be 
considered side by side with other (e.g., lay) values. This has contributed to the emergence of post-normal science [41] and the promotion of more interactive and inclusive forms of decision-making such as extended peer reviews, activist knowledge, etc. These processes bear the characteristics of deliberative decision-making and are favored by post-normal science scholars among other reasons due to their increased capacity to improve policy assessment by incorporating new types of knowledge. Moreover, deliberative processes are likely to generate decisions that are more acceptable, hence effective, due to their value-inclusive nature: experience shows that decision-making that excludes plural agent values is more likely to be perceived as illegitimate, meet resistance and not complied with [42].

Scholarly preference for deliberative decision-making has not been based merely on an appreciation of its substantive (improving policy quality) and instrumental (improving levels of policy acceptance via value inclusion) capacity, but perhaps more significantly on its democratic and legitimacy-bound significance. Deliberative democracy is embodied in the assumption that individuals can be transformed in the course of deliberative processes that bolster communicative rationality [39]. An effective and legitimate type of deliberation requires the absence of power and coercion, the predominance of rational argumentation and critical discussion in order to promote reflection and enable a change of preferences [39]. Such processes serve to formulate communicative rationalities that can then legitimately guide public decision-making. Importantly, 'the only condition for authentic deliberation is then the requirement that communication induces reflection upon preferences in non-coercive fashion' [39].

Deliberative democracy seems to have a considerable capacity for generating genuinely inclusive and deeply democratic institutions and political processes. Not surprisingly, then, deliberative decision-making has been strongly advocated as a way towards creating an authentically responsive and responsible democracy, which in turn has prompted practitioners (e.g., government officials, civil society, etc.) to devote time and energy for strengthening citizen engagement through deliberative forums. Ever since its inception, ecological economics has developed a distinguishable line of research that focuses on environmental decision-making through work on multi-criteria analysis and in particular participatory environmental decision-making. As a result, ecological economists have not overlooked these developments side-by-side with the growing social science literature on the role of participation in environmental governance.

\section{Deliberative Ecological Economics}

Ecological economists were quick to recognize the value of deliberative democracy for the study of environmental decision-making. The potential of deliberative processes to improve the legitimacy of policy decisions seems an obviously attractive prospect to a field long concerned with the legitimacy shortcomings of conventional methods of environmental decision-making such as cost-benefit analysis $[42,43]$. As the capacity of preference aggregation to provide a genuinely democratic means for capturing the social value of the environment comprises a main concern with such methods [26] the possibility of reflection and deliberation towards establishing some sort of 'consensus' group values advanced by deliberative decision-making unavoidably resulted attractive to ecological economists. Moreover, the communicative action view that preferences are formed during inter-subjective 
communication also coincides with ecological economists' insistence that rational action may be better understood as procedural rather than substantive [28]. The emphasis on considering preference formation as a process, instead of seeing preferences as a priori held like conventional environmental decision-making methods such as cost-benefit analysis do, has proved useful to ecological economics. As ecological economics has long held that preference formation is socially constructed through institutional influences [36,42] it has also argued that an attention at securing open, encompassing and democratic 'value articulating institutions' is crucial for legitimate and successful environmental decision-making [44]. Deliberative democracy's aim to pursue a public sphere of information, reflection, deliberation and consensual decision-making free of coercion as a policy objective, provides a pertinent model of such a desirable value articulating institution.

The view of preferences as procedurally-formed, non-aggregative and socially constructed and the suggestions in the deliberative democracy literature as regards desirable types of value articulating institutions prompted some ecological economists to consider using deliberative-type forums in order to study and elicit group environmental values via a method of 'deliberative environmental valuation' [45-47]. Deliberative valuation comprises an attempt to turn the value elicitation process into a preference-constructing process in order to deal with the issues that people do not hold pre-determined preferences towards the environment and that such preferences should be deliberatively derived [48]. Such attempts have provided interesting insights as regards the applicability and improvement of environmental valuation [49] but have also attracted scepticism over the potential to combine what appear to be two potentially conflictive processes of valuing the environment, namely the deliberative process of deliberative valuation and the calculative process of cost-benefit analysis and contingent valuation, [50] and whether such a method is trying to combine two incompatible valuation processes [51]. Some ecological economics scholars have even argued that in practice deliberative valuation serves to justify stated preference methods by adding often superficial forms of deliberation or discussion and that relevant studies in essence establish that the economic model they use is unsuitable for understanding particular sets of social values as regards the environment [52].

Ecological economists have also shown interest in combining multi-criteria analysis with deliberative processes in order to arrive at more 'precise' and legitimate environmental preferences [53]. This is not surprising given this methodology's concern with incorporating multiple values in environmental decision-making [54] and the interest of scholars in the potential of multi-criteria evaluation to transform policy analysis into a learning (communicative) process [55,56]. On the main, most attempts employ processes of deliberation and reflection for getting at a decision over the allocation of weights habitually used in multi-criteria analysis as a proxy for social preferences regarding the importance of the various goals that the model tries to satisfy. Relevant applications have proved useful for revealing the thinking and reasons lying behind environmental preferences [57], have shown potential to help understand crucial aspects of complex decision-making problems [58] and have produced critical insights regarding the contrast between stakeholder policy priorities (derived via deliberative multi-criteria analysis) and government allocations of available resources for tackling environmental issues [59]. Although this literature has not yet been critically assessed, the applicability of the criticism regarding the superficiality of deliberation raised against deliberative valuation should also be considered here - particularly for studies where deliberation is reduced to a one or two-day process. 
A further criticism of deliberative approaches to environmental valuation relates to issues of representation [43]. Work by social psychologists, for example, suggests that deliberative mechanisms function best when they involve small groups of no more than fifteen participants. It is important that a variety of perspectives be represented to facilitate dialogue and agreement across difference. In practice, deliberative groups often involve carefully selected stakeholders who are supposed to represent the beliefs and values of broader communities. Yet this raises the question as to whether groups of elite and sometimes self-selected stakeholders can reasonably act on behalf of society as a whole. Davies et al. [60] have proposed a way round this "representation problem" with the use of Q methodology prior to deliberation which helps choose representative viewpoints and participants for deliberative forums. Q methodology is a mixed quantitative and qualitative method used to study people's subjectivity by means of identifying the full range of discourses held around a topic (for more on $\mathrm{Q}$ see [61], which could allow designing deliberative forums that reflect a broad range of existing points of view around the issue at stake. Nevertheless, the representation problem is exacerbated by the high cost and demanding nature of deliberative processes, which can require multiple days of effort by the individuals involved.

A second area of enquiry of the literature that combines deliberation with ecological economics has recently emerged. This goes beyond the preference formation applications to focus on the study of the politics of sustainable development and their influences upon environmental policy decisions [48]. At the basis of the deliberative democracy paradigm lies an awareness of the need to acknowledge and legitimize plural values in public policy and decision-making. Several contributions in ecological economics share a concern towards the potential of today's materially-intensive and growth-oriented capitalist economy to achieve genuine 'green' outcomes [62] and its apparent failure to dematerialize [63]. Given that the imperatives or emergent properties sought by such a system may end up punishing the introduction of some types of necessary 'green' structures in the economy [39], the study of institutional orientations (rationalities) that do not exclude non-utilitarian values has become an important aspect of research in ecological economics [35,44].

This field has emphasised the need to investigate the politics of sustainability and in particular the linkages between these and environmental policy by stressing the importance [40] and showing the value [64] of embracing a plurality of epistemological and normative ideas, interpretations and practices as regards sustainable development. Furthermore, it has underlined the need to open up public spaces for debating and enacting a politics of sustainability that will advance the concept and practice of sustainable development [64]. Calls for value pluralism both in its epistemological and political dimensions also favour the adoption of critical views regarding the marginalisation of plural values as valid discourses and practices of sustainable development and raise attention to issues relating to conditions and principles that are necessary for facilitating deliberative sustainability politics. Contributions in this field of cross-fertilisation between ecological economics and deliberative democracy have examined the importance of inclusive discourses over policies addressing serious environmental challenges such as climate change [65] in an effort to identify policy principles better placed to facilitate inclusiveness of views and deliberation over sustainability. They have also examined the value of deliberative processes for encompassing a broad spectrum of epistemological perspectives in the diagnosis of environmental issues within the context of politically influential international initiatives such as the Millennium Ecosystem Assessment [64]. 
On-the-ground experience with deliberative forums for environmental planning, however, shows that formal and informal aspects of power prevent a fulfilment of public participation based on the power of citizens or the empowerment of weak groups in the sense of Habermasian communicative rationality [66]. This effect has been attributed to the fact that power relations are not simply left at the door of deliberative forums the moment that actors enter them but are instead brought into and end up significantly shaping deliberation processes. For example, dramaturgical behaviours [67] have been observed within deliberative forums, whereby front-stage performances or modes of interaction adopted by actors hide a very different power-shaped reality that exists at a back stage, although ironically those artificial front-stage attitudes are taken to represent reality. This is the case of business representatives in some deliberative forums who avoid openly expressing their values and objectives in the deliberative process thinking that they may be too conflictive and instead prefer "alternative communicative channels to make their 'substantive' representations" [68] to influential bodies such as government agencies. Moreover, the heavy focus on ways of improving and innovating the format of deliberative institutions seems to have resulted in deviating attention from thorny issues such as the study of forums' actual impacts on existing institutions and structures of decision-making [68], hence the argument that efforts which emphasise the fairness and competence of decision-making processes are important, but more basic questions regarding the distribution of political power (inside and outside deliberative forums) and the institutional capacity for democratic change need be addressed to fully consider the importance of deliberative institutions [68]. Similar points have been made in the past regarding ways in which the participatory management of local natural resources by village communities, which is now widely accepted as an institutional imperative in development initiatives, can exclude significant sections (e.g., women) and hence generate 'participatory exclusions' [69] and 'value exclusions' [70].

These points reflect a deeper, more conceptual criticism of Habermas's ideals regarding the creation of ideal public spaces as a goal for public policy for its failure to take into account the power dimensions of discourse in the sense meant by Foucault [71]. This perspective underlines the normative effects of discourses upon social practices, i.e., that particular discourses involve a language of power communicated by and embodied in the specifics of particular social practices (e.g., legal punishment). In that sense, scholars criticise deliberative ideals for failing to notice that "participation (or discourse) is constrained by, hides and at the same time perpetuates certain sets of power relations" [68]. As a result, contributions in the planning literature flag the concern that the result of struggling to find shared values through deliberative processes may sometimes be the silencing of values instead of giving them voice [72].

\section{A Deliberative Ecological Economics Research Agenda}

Deliberative ecological economics could be fruitfully advanced by researching the implications of deliberative procedures for preference formation and the politics of sustainability. In this section we outline several potential research priorities.

First, comparatively little empirical work has been conducted on the influence of deliberation on preference formation. One early contribution is Davis \& Whittington's [73] analysis of a public works project in Uganda. In this case, participation in structured community forums refined and enhanced 
respondents' willingness-to-pay as measured using stated preference techniques. On a different plain, Gregory \& Wellman [53] employed deliberative methods in a multicriteria decision analysis of wetlands restoration in coastal Oregon. Further examples are provided by Álvarez-Farizo \& Hanley's [74] case study of the Water Framework Directive and by Dietz et al.'s [75] analysis of people's preferences regarding climate change mitigation policy. See also Hermans et al.'s [76] study of watershed management in rural Vermont.

Concerning the second strand of research in deliberative ecological economics that focuses on the politics of sustainability, power-related issues are at the heart of concerns raised as regards the actual potential of deliberative processes for policy-making. As a result, a broader conceptual point as regards this second strand of research in deliberative ecological economics is that, given the centrality of power concerns in criticisms over the capacity of deliberative politics, researchers need to be clear about what they mean and understand as 'power' and 'politics'. Here, researchers could benefit from the work done in the field of political ecology which studies the relevance of power for environmental issues in particular looking at the influence of power over environmental change and conflict. For example, Paulson et al. [77] advance a political ecology approach to power that goes down two main lines of enquiry. First, in line with Hornborg's [78] definition of power as "a social relation built on an asymmetrical distribution of resources and risks," they emphasise the importance of exploring how power circulates among and between different social groups, resources, and spaces. This is a view of power as something that "presses on the subject from the outside, as what subordinates" [79] which has proved very useful for political ecology research. The second way of looking at power is by examining the ways people, resources, and places are constituted. This outlook follows Foucault's view that power is formative, that it becomes embodied in social practice (it can even literally form the shape of human bodies) and that in this twisted way it may be seen "as providing the very condition of [a subject's] existence and the trajectory of its desire" [79].

In turn, politics are "found in the practices and mechanisms through which power is circulated" [77]. Environmental politics in particular, are a contested and negotiated domain expressed in "the practices and processes through which power, in its multiple forms, is wielded and negotiated" [77] on multiple scales and contexts. These conceptualisations of power and politics are used to operationalise research on environmental change and conflict in order to better address practical problems such as resource degradation and social marginalization.

A useful concept here could be that of procedural power, i.e., this sort of "power which, in the face of complexity, is able nevertheless to impose a language of valuation determining which is the bottom-line in an ecological distribution conflict" [70]. Procedural power has been used to conceptualise the operation of particular decision-making 'shortcuts' (e.g., cost-benefit analysis) which attempt to circumvent the complexity of environmental issues and the 'stagnation' of public decision-making produced by conflict due to the existence of diverse and opposing environmental values. In that sense, the concept describes how such 'shortcuts' operate as mechanisms of power, reducing meaningful discussion and deliberation over environmental priorities and values down to expert-based scientific assessments (e.g., monetary assessments of environmental assets).

Considering the above-mentioned criticism of the real transformative potential of deliberative policy processes suggests that similar mechanisms of power may as well be operating within deliberative decision-making, whether these processes materialise in the form of deliberative assemblies or citizen 
juries. Research in deliberative ecological economics could focus on particular cases of deliberative forums for environmental governance and use participant observation (e.g., see [80]) of such forums to identify power and coercion mechanisms and analyse their operation in order to improve the democratic legitimacy and effectiveness of such processes. Another useful research priority could be to seek to establish what type of deliberative ecological economics most limits the influence of coercion and power by testing for example how different deliberative multi-criteria analysis designs affect power negotiation (e.g., during the phase of determining criteria weights) [58]. Nevertheless, any attempt focussing at improving the format of deliberative processes should keep in mind above-mentioned criticisms regarding the institutional relevance of such processes and the capacity for change of the broader institutional framework within which deliberation takes place [68]. In that sense, relevant research attempts in deliberative ecological economics should seek to critically understand and assess overarching institutional frameworks while exploring e.g., ideal deliberative multi-criteria designs.

From the above it becomes clear that balanced or shared power within deliberative forums is clearly one criterion for deliberative valuation or more broadly decision-making processes that are more likely to yield desirable sustainability policy outcomes in terms of legitimacy and effectiveness. Institutional relevance of deliberative processes, in terms of their outcomes substantially informing and if necessary changing existing policy priorities, practices, etc. could be another criterion of success. The capacity of deliberative processes to provide and open space both inside and outside forums for expressing, debating, and shifting values instead of silencing them or generating 'participatory exclusions' seems to be another important success criterion. Establishing the implications of continuing deliberations for the success of forums, which is difficult to grasp due to the fact that participants cannot a priori know the value of additional deliberations as the benefits of these cannot be known until they have already taken place, could provide information for developing further criteria of success of deliberative processes. Future research in deliberative ecological economics could seek to scrutinise the above and establish and test more such criteria via both theoretical investigations of the relevant literature, past deliberative initiatives, etc. and empirical testing of their significance in new settings (e.g., through case studies). Focusing deliberative ecological economics research towards deriving a robust set of criteria that yield deliberative decision-making successful could help not only boost the field's links to policy-making but also improve sustainability policy design and implementation.

Overall, the relevant literature that has developed during the last ten years or so seems to suggest that the ideal of communicative rationality is attractive and at least an attempt to approximate it seems an important goal that should be sought after with public policy [81]. However, observations regarding the influence of power on communicative planning practice essentially point out that deliberative inter-subjective communication and decision-making can be distorted by institutionalized forces or extra-institutional agents. Such distortion may involve not only direct exercise of power, but also manipulation, propaganda, deception, etc. that can result in the dominance of some ideas over others, which strips deliberation from its democratic potential. This is why advocates of deliberative decision-making complement communicative rationality with the requirement that reflection induced through inter-subjective communication is made in a non-coercive fashion and that it is free from deception, self-deception, strategizing, and manipulation in order to achieve genuinely democratic decisions [39]. Research in deliberative ecological economics could add to this direction by asking 
questions such as "why and how does power infiltrate deliberative decision-making over sustainability?" and could use case study research methods [82] to explore this.

There is one clear important sustainability policy implication of instituting deliberative democracy at the foundation of environmental policy and this is that decision-making processes should function as 'public spheres' for deliberation to take place and facilitate preference shifts. Deliberative policy analysts agree on the centrality of dialogue for legitimate decision-making and underline the importance of conceptual tools to make such dialogues possible. Building on work done in interpretive policy analysis [83] that puts emphasis on the meanings (imposed, challenged, intended and interpreted) of policies, deliberative policy analysis scholars have focused on discourse coalitions formed around different meanings of policies [84]. As preferences are seen to shape up in interaction, researchers suggest tools such as discourse analysis in order to analyze political formation, mutual positioning and the influence of particular policy discourses that bring together groups in the context of policy-making [71]. Such analyses explicitly attempt to identify the best means of integrating value pluralism in policy making by focusing on how 'identities of shared preferences' develop through deliberative decision-making processes. The objective is to learn more about the conditions where people re-position their distinct preferences during deliberation occurring in the context of interactive policy-making practices, particularly inside policy networks and the network society [85]. This is mostly done by looking at how conflicts of value pluralism and identity are dealt within such processes. Similar developments in ecological economics have underlined the value of $\mathrm{Q}$ methodology for identifying discourses and linking them to environmental policy in order to improve the latter's legitimacy by including plural and multiple values in sustainability policy [86]. Research in deliberative ecological economics could contribute to this by combining $\mathrm{Q}$ methodology with participant observation to explore the formation of discourse coalitions and the conditions under which this occurs in the form of people re-positioning their preferences inside deliberative forums in the absence of direct or indirect coercion.

Whereas the first strand of research in deliberative ecological economics focuses on bringing in deliberation for improving the study of preference formation, the second strand of this field is concerned with the analysis of sustainability policy and politics. This strand uses insights on deliberation from the broader body of social science (political science, planning literature, human geography, etc.) to study more 'traditional' ecological economics issues and in particular issues related to sustainability decision-making. The relative 'novelty' of this strand is that by postulating desirable sustainability governance as deliberative it focuses attention on analysing the absence of deliberation in sustainability governance or deficiencies of existing deliberative processes. To do so, it employs the notion of procedural power, i.e., the power to decide which method or principle of environmental valuation is relevant for sustainability decision-making, that has been distinctively developed within ecological economics [70] to address the need to avoid value-excluding decision-making (e.g., one based upon cost-benefit analysis) and explain mechanisms within the sphere of public decision-making that generate ecological distribution conflicts. In particular, this strand of deliberative ecological economics seeks to analyse how decision-making shortcuts and bottom-lines (such as cost-benefit evaluations) explain deliberation absence or deficiencies and understands these by recourse to a political ecology explanatory framework of power and politics. As a result, the second strand of deliberative ecological economics research is important for ecological economics as it aspires to fill in 
the research gap of studying procedural power through a combined political ecology/ecological economics approach as advocated by Martinez-Alier [70]. In that sense, this strand tries to answer two important research questions posed by ecological economics, namely the one regarding who has the power to decide sustainability decision-making procedures and "who has the power to simplify complexity ruling some languages of valuation out of order?" [70].

\section{Conclusions}

Deliberative ecological economics has sprung out of the preoccupation of some ecological economists with environmental value exclusion effects of the reductionist model of rational human action employed by mainstream economics to analyse environmental policy. Considering rational action as an attempt to reach understanding between oneself and others via inter-subjective communication, deliberative democracy postulates that decision-making processes should generate public spheres that establish conditions promoting debate of actors' values and preferences in order to facilitate reflection and preference shift with a view to some sort of future consensus. Ecological economists have used those insights to improve research on the formation of social preferences towards the environment by introducing deliberation in environmental valuation exercises and in the course of developing multi-criteria analysis models. Other ecological economists focus on another aspect of deliberative environmental decision-making, namely its capacity to produce nuanced, comprehensive and inclusive visions of environmental issues, integrated into current political processes.

However, work in deliberative environmental preference formation has been criticised for trying to combine two conflictive processes of valuing the environment (deliberation and monetary valuation) which results in many studies trying to justify stated preferences methods by often involving superficial levels of deliberation. Moreover, criticisms from the environmental planning literature suggest that deliberative political decision-making processes often fail as they ignore the practical context of power surrounding and pervading environmental planning. To this end, it seems valuable that future research in this field considers how power intrudes actual deliberative processes of environmental decision-making in an effort to release their full democratic and transformative potential. Further work along those lines can help advance both the newly-formed field of deliberative ecological economics and improve knowledge and practice of environmental governance.

\section{Acknowledgements}

We would like to thank the two anonymous reviewers as well as the Editor of this Special Issue Robert Krueger for their genuinely constructive and useful comments.

\section{References and Notes}

1. The choice of the commoner's gender is Hardin's.

2. Emphasis in the original.

3. Hardin, G. The tragedy of commons. Science 1968, 162, 1243-1248.

4. Paavola, J.; Bromley, D. Contested choices. In Economics, Ethics, and Environmental Policy; Paavola, J., Bromley, D., Eds; Blackwell: Oxford, UK, 2002; pp. 3-13. 
5. Ecological Economics: The Science and Management of Sustainability; Costanza, R.C., Ed.; Columbia University Press: New York, NY, USA, 1991.

6. Norgaard, R.B.; Howarth, R.B. Resolving economic and environmental perspectives on the future. Res. Soc. Prob. Public Policy 1993, 5, 225-241.

7. Daly, H.E. Steady-State Economics: The Economics of Biophysical Equilibrium and Moral Growth; WH Freeman: New York, NY, USA, 1977.

8. Funtowicz, S.O.; Ravetz, J.R. A new scientific methodology for global environmental issues. In Ecological Economics: The Science and Management of Sustainability; Costanza, R., Ed.; Columbia University Press: New York, NY, USA, 1991; pp. 137-152.

9. Deliberative Ecological Economics; Zografos, C., Howarth, R.B., Eds.; Oxford University Press: Delhi, India, 2008.

10. Bromley, D.W. Making the Commons Work; ICS Press: San Francisco, CA, USA, 1992.

11. Monbiot, G. The tragedy of enclosure. Sci. Am. 1994, Jan, 1-2.

12. Franke, R.; Chasin, B. Peasants, peanuts, profits and pastoralists. Ecologist 1981, 11, 156-168.

13. Kirkby, J.; O'Keefe, P.; Timberlake, L. The Earthscan Reader in Sustainable Development; Earthscan: London, UK, 1995.

14. Thomas, D.S.G.; Middleton, N.J. Desertification: Exploding the Myth; John Wiley \& Sons: Chichester, UK, 1994.

15. Simon, H.A. Models of Man: Social and Rational; John Wiley \& Sons: New York, NY, USA, 1957.

16. Wolfensohn, J.D. Global Priority. Our Planet 2002, 13. Available online: http://www.ourplanet.com/imgversn/133/wolf.html (accessed on 29 October 2010).

17. Griffiths, P.; Fox, A.; Hindle, S. The Experience of Authority in Early Modern England; St. Martin's Press: New York, NY, USA, 1996.

18. Agarwal, A.; Narain, S. Global Warming in an Unequal World: A Case of Environmental Colonialism; Centre for Science and Environment: Delhi, India, 1991.

19. Pedace, R.; Vaughan, B.; Doherty, A. Climate Debt: Making Historical Responsibility Part of the Solution; Friends of the Earth International: Amsterdam, The Netherlands, 2005.

20. Walker, G. Beyond distribution and proximity: Exploring the multiple spatialities of environmental justice. Antipode 2009, 41, 614-636.

21. Spash, C.L.; Hanley, N. Preferences, information and biodiversity preservation. Ecol. Econ. 1995, 12, 191-208.

22. Paavola, J. Towards sustainable consumption: Economics and ethical concerns for the environment in consumer choices. Rev. Soc. Econ. 2001, 59, 227-248.

23. Edwards-Jones, G.; Davies, B.; Hussain, S. Ecological Economics: An Introduction; Blackwell: Oxford, UK, 2000.

24. Spash, C.L. Investigating individual motives for environmental action: Lexicographic preferences, beliefs and attitudes. In Ecological Sustainability and Integrity: Concepts and Approaches; Lemons, J., Westra, L., Goodland, R., Eds.; Kluwer Academic Publishers: Dordrecht, The Netherlands, 1998; pp. 46-62.

25. Hargreaves-Heap, S.H.; Hollis, M.; Lyons, B.; Sugden, R.; Har Weale, A. The Theory of Choice: A Critical Guide; Blackwell: Oxford, UK, 1992. 
26. Martinez-Alier, J.; Munda, G.; O’Neill, J. Incommensurability of Values in Ecological Economics; Edward Elgar: Cheltenham, UK, 1999; pp. 37-57.

27. Howarth, R.B. Sustainability under uncertainty: A deontological approach. Land Econ. 1995, 71, 417-427.

28. Van den Bergh, J.C.J.M.; Ferrer-i-Carbonell, A.; Munda, G. Alternative models of individual behaviour and implications for environmental policy. Ecol. Econ. 2000, 32, 43-61.

29. Baker, R. Economic Rationality and Health and Lifestyle Choices for People with Diabetes: A Q Methodological Investigation. Presented at the 20th Annual Conference of the International Society for the Scientific Study of Subjectivity, Athens, GA, USA, 23-25 September 2004.

30. Nyborg, K.; Howarth, R.B.; Brekke, K.A. Green consumers and public policy: On socially contingent moral motivation. Resour. Energ. Econ. 2006, 28, 351-366.

31. Turaga, R.; Howarth, R.B.; Borsuk, M.E. Pro-environmental behavior: Rational choice meets moral motivation. Ann. N. Y. Acad. Sci. 2010, in press.

32. Norton, B.G. Sustainability: A Philosophy of Adaptive Management; University of Chicago Press: Chicago, IL, USA, 2005.

33. Dewey, J. The Public and Its Problems; Holt: New York, NY, USA, 1927.

34. O'Neill, J. Ecology, Policy and Politics: Human Well-being and the Natural World; Routledge: Abingdon, UK, 1993.

35. O’Neill, J.; Spash, C.L. Appendix: Policy research brief conceptions of value in environmental decision-making. Environ. Value. 2000, 9, 521-536.

36. Vatn, A. Rationality, institutions and environmental policy. Ecol. Econ. 2005, 55, 203-217.

37. Habermas, J. The Theory of Communicative Action; Beacon Press: Boston, MA, USA, 1984.

38. Walzer, M. Spheres of Justice: A Defense of Pluralism and Equality; Basic Books: New York, NY, USA, 1983.

39. Dryzek, J. Deliberative Democracy and Beyond: Liberals, Critics and Contestations; Oxford University Press: Oxford, UK, 2000.

40. Sneddon, C.; Howarth, R.B.; Norgaard, R.B. Sustainable development in a post-Brundtland world. Ecol. Econ. 2006, 57, 253-268.

41. Funtowicz, S.O.; Ravetz, J.R. Science for the post-normal age. Futures 1993, 25, 739-755.

42. Paavola, J.; Adger, W.N. Institutional Ecological Economics. Ecol. Econ. 2005, 53, 353-368.

43. Howarth, R.B.; Wilson, M.A. A theoretical approach to deliberative valuation: Aggregation by mutual consent. Land Econ. 2006, 82, 1-16.

44. Vatn, A. Institutions and the Environment; Edward Elgar: Cheltenham, UK, 2005.

45. Wilson, M.A.; Howarth, R.B. Discourse-based valuation of ecosystem services: Establishing fair outcomes through group deliberation. Ecol. Econ. 2002, 41, 431-443.

46. Aldred, J.; Jacobs, M. Citizens and wetlands: Evaluating the Ely citizens' jury. Ecol. Econ. 2000, 34, 217-232.

47. Sagoff, M. Aggregation and deliberation in valuing environmental public goods: A look beyond contingent pricing. Ecol. Econ. 1998, 24, 213-230.

48. Zografos, C.; Howarth, R.B. Towards a deliberative ecological economics. In Deliberative Ecological Economics; Zografos, C., Howarth, R.B., Eds.; Oxford University Press: Delhi, India, 2008; pp. 1-20. 
49. MacMillan, D.; Hanley, N.; Lienhoop, N. Contingent valuation: Environmental polling or preference engine? Ecol. Econ. 2006, 60, 299-307.

50. Holland, A. The foundations of environmental decision-making. Int. J. Environ. Pollut. 1997, 7, 483-496.

51. O'Connor, M. Pathways for environmental evaluation: A walk in the (Hanging) Gardens of Babylon. Ecol. Econ. 2000, 34, 175-193.

52. Spash, C. Deliberative monetary valuation: Literature, limitations and perspectives. In Deliberative Ecological Economics; Zografos, C., Howarth, R.B., Eds.; Oxford University Press: Delhi, India, 2008; pp. 21-49.

53. Gregory, R.; Wellman, K. Bringing stakeholder values into environmental policy choices: A community-based estuary case study. Ecol. Econ. 2001, 39, 37-52.

54. Munda, G. Social Multi-Criteria Evaluation for a Sustainable Economy; Springer-Verlag: Heidelberg, Germany, 2008.

55. Munda, G.; Russi, D. Social multicriteria evaluation of conflict over rural electrification and solar energy in Spain. Environ. Plan. C 2008, 26, 712-727.

56. Gamboa, G.; Munda, G. The problem of windfarm location: A social multi-criteria evaluation framework. Energ. Policy 2007, 35, 1564-1583.

57. Kenyon, W. Evaluating flood risk management options in Scotland: A participant-led multi-criteria approach. Ecol. Econ. 2007, 64, 1-81.

58. Proctor, W.; Drechsler, M. Deliberative multi-criteria evaluation. Environ. Plan. C 2006, 24, 169-190.

59. Cook, D.; Proctor, W. Assessing the Threat of Exotic Plant Pests. Ecol. Econ. 2007, 63, 594-604.

60. Davies, B.B.; Sherlock, K.; Rauschmayer, F. Recruitment, composition, and mandate issues in deliberative processes: Should we focus on arguments rather than individuals? Environ. Plan. C 2005, 23, 599-615.

61. Zografos, C. Rurality discourses and the role of the social enterprise in regenerating rural Scotland. J. Rural Stud. 2007, 23, 38-51.

62. O'Connor, M. Is Capitalism Sustainable? Political Economy and the Politics of Ecology; Guilford Press: New York, NY, USA, 1994.

63. Roca, J.; Padilla, E.; Farre, M.; Galletto, V. Economic growth and atmospheric pollution in Spain: Discussing the environmental Kuznets curve hypothesis. Ecol. Econ. 2001, 39, 85-99.

64. Norgaard, R. Deliberative economics Kenneth E. Boulding Lecture delivered at the 9th Biennial Meeting of ISEE, December 2006, Delhi, India. Ecol. Econ. 2007, 63, 375-382.

65. Riedy, C. A developmental perspective on climate policy discourse. In Deliberative Ecological Economics; Zografos, C., Howarth, R.B., Eds.; Oxford University Press: Delhi, India, 2008; pp. 167-193.

66. Pløger, J. Public participation and the art of governance. Environ. Plan. B 2001, 28, 219-241.

67. Goffman, E. The Presentation of the Self in Everyday Life; Penguin Books: London, UK, 1969.

68. Bickerstaff, K.; Walker, G.P. Shared visions, unholy alliances: Power, governance and deliberative processes in local transport planning. Urban Stud. 2005, 42, 2133-2144.

69. Agarwal, B. Participatory exclusions, community forestry, and gender: an analysis for South Asia and a conceptual framework. World Dev. 2001, 29, 1623-1648. 
70. Martinez-Alier, J. The Environmentalism of the Poor; Edward Elgar Publishing: North Hampton, NH, USA, 2002.

71. Hajer, M.; Versteeg, W. A decade of discourse analysis of environmental politics: Achievements, challenges, perspectives. J. Environ. Policy Plan. 2005, 7, 175-184.

72. Tewdwr-Jones, M.; Allmendinger, P. Deconstructing communicative rationality: A critique of Habermasian collaborative planning. Environ. Plan. A 1998, 30, 1975-1989.

73. Davis, J.; Whittington, D. A comparison of participatory group meetings and contingent valuation surveys: A case study of Lugazi, Uganda. Econ. Dev. Cult. Change 1997, 46, 73-94.

74. Álvarez-Farizo, B.; Hanley, N. Improving the process of valuing non-market benefits: Combining citizens' juries with choice modelling. Land Econ. 2006, 82, 465-478.

75. Dietz, T.; Stern, P.C.; Dan, A. How deliberation affects stated willingness to pay for mitigation of carbon dioxide emissions: An experiment. Land Econ. 2009, 85, 329-347.

76. Hermans, C.; Howarth, R.B.; Noordewier, T.; Erickson, J.D. Constructing preferences in structured group deliberative processes. In Deliberative Ecological Economics; Zografos, C., Howarth, R.B., Eds.; Oxford University Press: Delhi, India, 2008; pp. 50-79.

77. Paulson, S.; Gezon, L.L.; Watts, M. Locating the political in political ecology: An introduction. Hum. Organ. 2003, 62, 205-217.

78. Hornborg, A. The power of the machine. In Global Inequalities of Economy, Technology and Environment; Altamira: Walnut Creek, CA, USA, 2001.

79. Butler, J. The Psychic Life of Power; Stanford University Press: Palo Alto, CA, USA, 1997.

80. Peacock, J. The Anthropological Lens: Harsh Light, Soft Focus; Cambridge University Press: Cambridge, UK, 1986.

81. Innes, J.; Booher, D. Consensus building and complex adaptive systems: A framework for evaluating collaborative planning. JAPA 1999, 65, 412-423.

82. Yin, R. Case Study Research: Design and Methods; Sage Publications: Thousand Oaks, CA, USA, 2003.

83. Conducting Interpretive Policy Analysis; Yanow, D., Ed.; Sage Publications: Newbury Park, CA, USA, 2000.

84. Deliberative Policy Analysis; Hajer, M., Wagenaar, H., Eds.; Cambridge University Press: Cambridge, UK, 2003.

85. Hajer, M. A frame in the fields: Policymaking and the reinvention of politics. In Deliberative Policy Analysis; Hajer, M., Wagenaar, H., Eds.; Cambridge University Press: Cambridge, UK, 2003; pp. 88-110.

86. Barry, J.; Proops, J. Seeking sustainability discourses with Q methodology. Ecol. Econ. 1999, 28, 337-345.

(C) 2010 by the authors; licensee MDPI, Basel, Switzerland. This article is an open access article distributed under the terms and conditions of the Creative Commons Attribution license (http://creativecommons.org/licenses/by/3.0/). 